\title{
MNREL
}
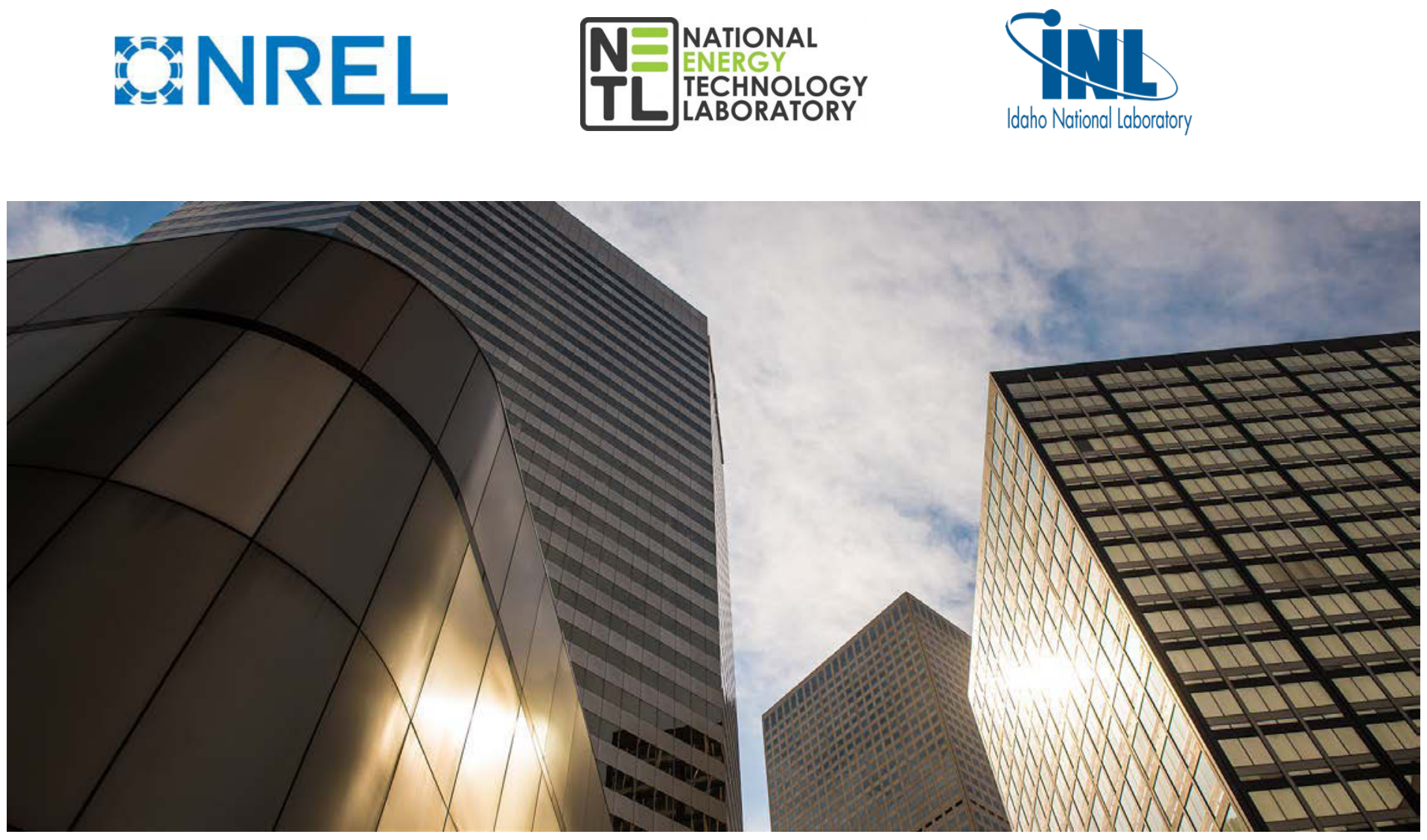

\section{Summary Report of the Tri-Lab Workshop on R\&D Pathways for Future Energy Systems, July 24-25, 2018}

Douglas Arent, ${ }^{1}$ Peter Balash, ${ }^{2}$ Richard Boardman, ${ }^{3}$ Shannon Bragg-Sitton, ${ }^{3}$ Jill Engel-Cox, ${ }^{1}$ David Miller, ${ }^{2}$ and Mark Ruth ${ }^{1}$

1 National Renewable Energy Laboratory

2 National Energy Technology Laboratory

3 Idaho National Laboratory

NREL is a national laboratory of the U.S. Department of Energy Office of Energy Efficiency \& Renewable Energy

Operated by the Alliance for Sustainable Energy, LLC

This report is available at no cost from the National Renewable Energy Laboratory (NREL) at www.nrel.gov/publications.
Technical Report

NREL/TP-6A70-72926

INL/EXT-18-52273

DOE/NETL-2019/2046

December 2018 


\section{GNREL}

Summary Report of the Tri-Lab Workshop on R\&D Pathways for Future Energy Systems, July 24-25, 2018

Douglas Arent, ${ }^{1}$ Peter Balash, ${ }^{2}$ Richard Boardman, ${ }^{3}$ Shannon Bragg-Sitton, ${ }^{3}$ Jill Engel-Cox, ${ }^{1}$ David Miller, ${ }^{2}$ and Mark Ruth ${ }^{1}$

1 National Renewable Energy Laboratory

2 National Energy Technology Laboratory

3 Idaho National Laboratory

\section{Suggested Citation}

Arent, Douglas, Peter Balash, Richard Boardman, Shannon Bragg-Sitton, Jill Engel-Cox, David Miller, and Mark Ruth. 2018. Summary Report of the Tri-Lab Workshop on R\&D Pathways for Future Energy Systems, July 24-25, 2018. Golden, CO: National Renewable Energy Laboratory. NREL/TP-6A70-72926. https://www.nrel.gov/docs/fy19osti/72926.pdf.

NREL is a national laboratory of the U.S. Department of Energy Office of Energy Efficiency \& Renewable Energy Operated by the Alliance for Sustainable Energy, LLC

This report is available at no cost from the National Renewable Energy Laboratory (NREL) at www.nrel.gov/publications.

Contract No. DE-AC36-08GO28308
Technical Report

NREL/TP-6A70-72926

INL/EXT-18-52273

DOE/NETL-2019/2046

December 2018

National Renewable Energy Laboratory 15013 Denver West Parkway Golden, CO 80401

303-275-3000 • www.nrel.gov 


\section{NOTICE}

This work was authored in part by the National Renewable Energy Laboratory, operated by Alliance for Sustainable Energy, LLC, for the U.S. Department of Energy (DOE) under Contract No. DE-AC36-08GO28308; in part by the Idaho National Laboratory, operated by Battelle Energy Alliance, LLC for the U.S. Department of Energy under Contract No. DE-AC07-05ID14517; and in part by MESA for the U.S. Department of Energy National Energy Technology Laboratory under Contract No. DE-FE0025912. Partial funding provided by the U.S. Department of Energy Office of Energy Efficiency and Renewable Energy. The views expressed herein do not necessarily represent the views of the DOE or the U.S. Government. The U.S. Government retains and the publisher, by accepting the article for publication, acknowledges that the U.S. Government retains a nonexclusive, paid-up, irrevocable, worldwide license to publish or reproduce the published form of this work, or allow others to do so, for U.S. Government purposes.

This report is available at no cost from the National Renewable Energy Laboratory (NREL) at www.nrel.gov/publications.

U.S. Department of Energy (DOE) reports produced after 1991 and a growing number of pre-1991 documents are available free via www.OSTI.gov.

Cover photo by Dennis Schroeder: NREL 39578.

NREL prints on paper that contains recycled content. 


\section{Executive Summary}

Under Secretary of Energy Menezes called for an integrated view of U.S. Department of Energy (DOE) applied energy activities and requested that the three applied energy laboratories - Idaho National Laboratory (INL), the National Energy Technology Laboratory (NETL), and the National Renewable Energy Laboratory (NREL) - take a fresh look at their portfolios for gaps and coordination opportunities. A workshop was held July 24-25, 2018 with teams from DOE, INL, NETL, and NREL. Workshop participants identified key technical areas and outlined several priority research and development (R\&D) areas, including:

- Integrated systems modeling, analysis, and optimization, including developing tools for unprecedented understanding and optimal management of the U.S. energy infrastructure and interdependencies

- Integrated systems engineering, development and testing, including developing and investing in validation of new architectural frameworks across all supply and use sectors

- Innovative, core, multi-sector and multi-program technologies, including developing technologies that will enable highly efficient, resilient, and affordable tightly coupled energy systems.

- Approaches for security and resilience of integrated energy systems.

Workshop participants identified numerous unique, high-leverage, collaborative R\&D areas. Exemplary Grand Challenges \& Opportunities for an Integrated Energy Systems Initiative include:

- R\&D roadmaps for new technologies and approaches - e.g. heat integration, hydrogen, natural gas utilization, and dynamic interactions with the grid

- Roadmaps for transition to future energy systems addressing security, resilience and reliability

- New energy analytic optimization tool sets that reflect emerging energy system interdependencies and complexities

- Coupling energy, water, fuels, transportation, smart buildings and transmission, distribution, and communications models to understand cross-system effects (e.g., high penetration of DER on transmission)

- Validated design strategies to meet resiliency and reliability standards for tightly coupled and coordinated energy systems

- Architectures and next-generation, real time, adaptive control frameworks for clean, resilient and secure coupled and coordinated energy systems of 2030 and beyond

- New class of scalable sensor control devices and frameworks to impact and enable current and future systems, including ultra low-cost sensors and sensors that are accurate through disturbances to transform system resilience and reliability

- Continental data analytics and information framework for $100 \%$ visibility of the entire U.S. energy system. 
Further, across a broad range of materials, process and cyber related R\&D areas that would uniquely accelerate Integrated Energy Systems, additional high impact opportunities identified include:

- Developing new materials, processes and systems for carbon utilization

- Designing, building and validating tightly coupled, carbon dioxide $\left(\mathrm{CO}_{2}\right)$ utilization, multi-product, resilient systems

- Designing, building and validating system operations, economic functionality and control strategies to meet resilience and reliability standards for tightly coupled and coordinated energy systems

- Designing, building and validating tightly coupled, low emission, multi-product, high thermal output resilient systems

- Advancing distributed hydrogen-based fuel cell technologies within integrated delivery systems

- Advanced separations technologies of ores and waste materials to select critical materials

- New hybrid technologies for produced, waste, and cooling water treatment, utilization, and recycling

- Combining microbes and waste carbon monoxide $(\mathrm{CO})$ and $\mathrm{CO}_{2}$ for manufacture of high value products in integrated carbon capture, utilization, and sequestration (CCUS) systems

- Delivering new capabilities to design, test and validate new materials for extreme environments

- Delivering opensource software platforms for high performance computing (HPC) materials design tools (50x speedup)

- Coupling additive manufacturing, supply chain knowledge, and molecular and device simulation, testing and validation for integrated energy systems

- Designing and validating integrated hydrogen production, delivery, utilization, and storage systems

Finally, workshop participants indicated a critical next step would be to develop an R\&D roadmap for an "Integrated Energy System Initiative" to inform an initial multi-year program plan (MYPP). 


\section{Table of Contents}

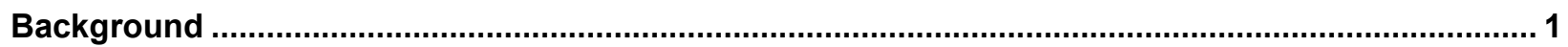

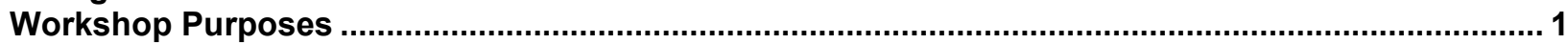

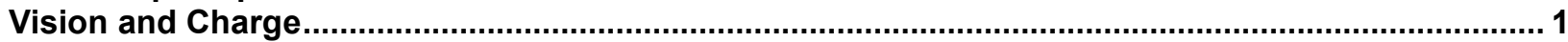

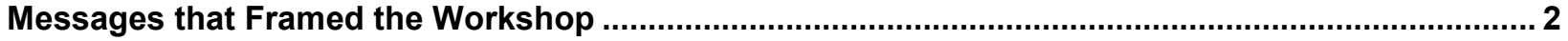

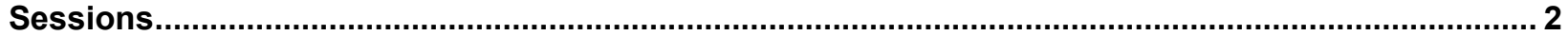

Session 1. Challenges and Perspectives from the Applied Offices ................................................... 2

Session 2. Lab Perspective on Opportunities for Collaborative R\&D ...............................................5

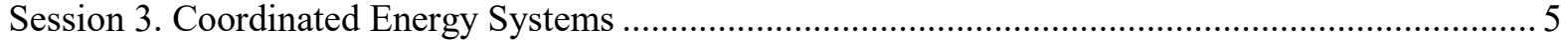

Session 4. Tightly Coupled Hybrid Energy Systems ….................................................................... 6

Session 5. Technology Development Opportunities ...................................................................... 8

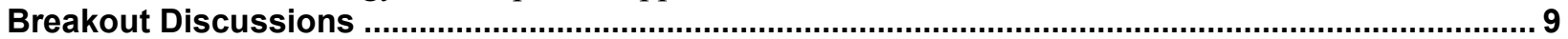

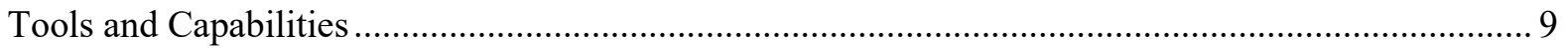

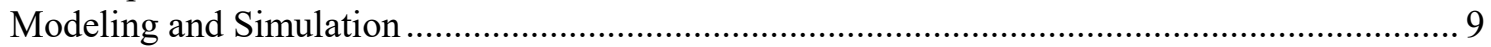

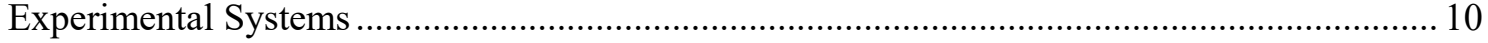

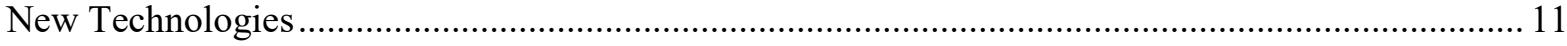

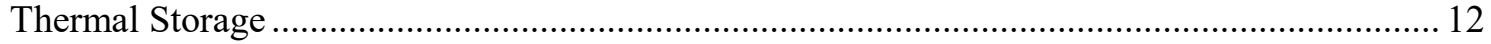

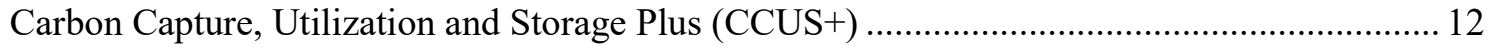

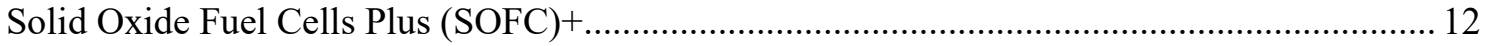

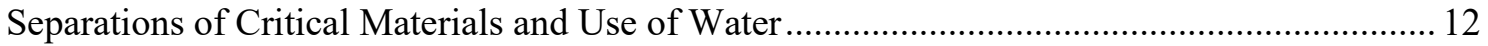

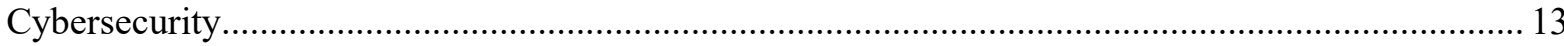

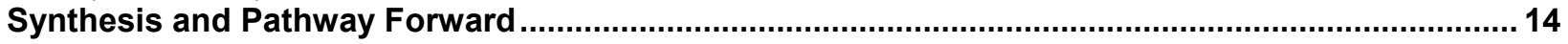




\section{Background}

The world relies on energy for every aspect of life and for well-being. Given impetus from the DOE Undersecretary for Energy, the lab directors for the three applied energy DOE laboratories - Idaho National Laboratory (INL, nuclear), the National Energy Technology Laboratory (NETL, fossil), and the National Renewable Energy Laboratory (NREL, renewables) - agreed to organize and advance cooperation among the laboratories (labs) to help the nation maintain and increase American prosperity through development of the nation's future energy systems. Accordingly, laboratory fellows and initiative leads from each of the labs were asked to organize and participate in a meeting to (1) help establish a broader inter-lab team for performing technical and economic assessments of future energy infrastructure buildout and (2) identify priority areas for collaborative technology development that will enable U.S. industry to better utilize the spectrum of U.S. natural resources in achieving energy security, ensuring economic stability, and addressing environmental sustainability for the foreseeable future.

This report summarizes the viewpoints, discussion topics, and recommendations from the workshop held July 24-25, 2018 at NREL facilities in Golden, Colorado. The workshop included Undersecretary Menezes, the Assistant Secretaries (or their representatives) for DOE Offices of Nuclear Energy (NE), Fossil Energy (FE), Energy Efficiency and Renewable Energy (EERE), and Electricity (OE); a few DOE deputy assistant secretaries and program directors; and the laboratory director from each of the applied energy labs. Approximately 12-15 program and technology development managers or leads from each lab also participated in the meeting.

\section{Workshop Purposes}

1. To identify unique multi-programmatic R\&D opportunities across FE, NE, OE, and EERE science and technology (S\&T) areas that would be valuable to DOE and the nation

2. To inform DOE S\&T roadmap efforts and advance program concepts for collaborative, multi-lab R\&D that serves the nation.

\section{Vision and Charge}

Two themes underscore the value proposition of the national laboratories, innovation and cooperation.

In recent years, the labs have shown effective cooperation under crosscutting programs such as the Grid Modernization Laboratory Consortium and the Carbon Capture Simulation Initiative. However, significant opportunities still exist to work collaboratively to develop solutions and identify technology pathways to reach DOE's goals, which include developing a holistic future energy infrastructure capable of achieving the fullest potential of the country's energy resources across the entire energy sector, which includes the electrical grid, industry, and transportation systems. 
Identification, analysis, and optimization of our future energy systems can only be achieved by understanding the natural resource potential of the United States, and the potential role and benefits of current, emerging, nascent, and yet-to-be-developed technologies. Analysis is crucial to understanding resource production and conversion pathways, and to identifying technology gaps, which in turn spurs innovation and technology inventions. In addition, analysis can help inform stakeholders across industry and local, regional, and national institutions, as well as U.S. citizens and their representative decision makers of the benefits and impacts of energy use, technology choices, and system dependencies.

Innovation is the key to designing, developing, and deploying the energy systems of the future that will be efficient, flexible, reliable, resilient, secure, economically competitive, and meet environmental protection standards.

\section{Messages that Framed the Workshop}

- Well-articulated vision and objectives of our future energy system will help drive S\&T and $R \& D$ roadmaps and investments.

- Deeper cross-program and multidisciplinary expertise will be crucial to elucidating complex technical $R \& D$ roadmaps.

- There are multiple options to advance and utilize U.S. energy resources.

- Through technology innovation, the U.S. energy sector continues to evolve and is now accomplishing breakthroughs once considered infeasible (e.g., natural gas/oil export).

- Innovation options should not be pigeonholed in one sector-there are compelling needs and motivation for integrated systems thinking.

- Innovation requires new technologies and establishing the right policies, markets, and regulations.

- Fossil, nuclear, and renewable energy each have their own challenges, but all will have roles in our energy future.

- The future electricity grid will play the significant role of ensuring an economic, secure, and reliable integrated energy system, but system-level solutions must be found to address increasingly complex reliability and security challenges.

The energy systems of the future will require a collaborative effort that includes fossil, nuclear, and renewables to achieve needed and desired technological goals and advancements. In addition to working with each other, the labs need to continue to engage with other agencies (e.g., U.S. Department of the Interior, U.S. Department of Commerce, U.S. Environmental Protection Agency, Federal Energy Regulatory Commission, and U.S. Department of Transportation) and external stakeholders to ensure a reliable energy future.

\section{Sessions}

\section{Session 1. Challenges and Perspectives from the Applied Offices}

Fossil, nuclear, and renewable energy all face challenges with regard to their inclusion in future energy systems. The current core challenges with large-scale thermal generation are economic competitiveness and flexible operation of nuclear and coal. Several light water reactors have recently been shut down in advance of their license expiration, and potential closures have been announced for as many as a dozen additional plants. Coal plant retirements continue to occur as 
a result of historically low natural gas prices, rising plant maintenance, and increasingly stringent environmental standards. To help address these issues, smaller, more flexible modular units to increase efficiency, improve economics, reduce environmental impacts, and advance versatility are being explored. R\&D pathways for future energy systems were discussed, and the need to develop a roadmap with success indicators was highlighted. Renewables face continuing challenges related to grid integration, curtailment and cost-effectively meeting increased loads associated with transportation and industrial electrification.

Perspectives presented during the session includes:

- Key NE R\&D areas identified included advanced fuels, materials and instrumentation, plant life extensions, enhanced safety, economics, and advanced and small modular reactors development, including megawatt-scaleup expanded uses for nuclear energy.

○ Notable discussion points included:

- Nuclear power in the United States has been trending downward in recent years, with the total generation being maintained through power uprates and efficiency improvements.

- The U.S. nuclear energy industry is considered the most qualified and can supply the safest most-advanced technology, but the United States is losing global markets and international influence as some countries are accelerating new reactor deployments and offering take-back of spent fuel.

- Three major challenges facing nuclear energy in the United States are (1) the cost of new reactor construction (due to new reactor design inadequacy, joint plant siting and operating permit requirements, and a largely inexperienced construction workforce), (2) limited domestic materials supply chain industries, and (3) lack of a clear path to final dispositioning of spent fuel.

- Industry use of heat, steam, and electricity requires delivery systems that have not been developed or demonstrated.

- Key FE R\&D areas identified included flexible operations, machine learning, advanced turbines, fuel cells, $\mathrm{CO}_{2}$ capture and utilization, and hydrogen.

- Notable discussion points included:

- Coal plants in the 21 st century will be modular with increased efficiency, the ability to cycle, and reduced emissions. They will have carbon capture and storage.

- Oil and gas will benefit from big data and predictive analysis to increase extraction efficiency above the current $10 \%$ for tight oil and gas reservoirs.

- Key EERE R\&D areas included integration of renewable energy with the broader grid, avoiding curtailment of renewables when generation exceeds demand, establishing new transmission and electricity distribution networks, and transportation and industry electrification.

○ Notable discussion points included:

- Core technologies are poised for further increases in productivity and efficiency.

- High performance computing is enabling integration. 
- Advanced controls and more-sophisticated operating systems enable renewables to offer new services to the grid.

- Key OE R\&D areas identified included ensuring grid and microgrid reliability and resiliency, advanced distributed control systems, energy storage, and transactive energy.

- Notable discussion points included:

- Computing and artificial intelligence/machine learning will play an increasingly important role in grid design, simulation, and management.

- OE is addressing North American grid vulnerability.

- Megawatt-storage is becoming increasingly valuable.

- Cybersecurity is critical; there is a need to work closely with new DOE Office of Cybersecurity, Energy Security, and Emergency Response.

- Future energy systems will need to be more flexible and more secure.

Possible areas of collaboration identified include:

- Development of technical and functional and operating requirements (F\&OR)

- Modular technology advancement and advanced manufacturing

- Hybrid/integrated systems design, evaluation, and demonstration

- Grid integration, and reliability; grid stability and grid services

- Energy storage at scales ranging from seconds to seasonal

- Carbon utilization - for example, capture (FE), bioengineering (EERE), and thermal energy substitution of combustion sources of heat (NE)

- Modeling, simulation, and optimization

- Advanced materials

- Food-energy-water nexus

- Next-generation batteries or other electric storage devices

- Thermal and chemical energy storage.

In summary, there are multiple potential areas of collaboration for the applied energy labs. The workshop participants were able to identify and expand on some, but not all, the areas where crosscutting lab efforts could be beneficial. Open cross-lab communication and industry involvement will be key to advancing the future of nuclear, fossil, and renewable energy systems. Furthermore, the co-development of computational tools; the co-development of shared, collaborative testing and demonstration facilities; and the transfer of technologies should be a priority. Such collaborations should be both among the DOE laboratories and also with industry as key partners. Technology decisions need to be science-based but should engage stakeholders and consider interactions with current and potential markets and policies at the federal and state levels. 


\section{Session 2. Lab Perspective on Opportunities for Collaborative R\&D}

The three laboratories offered broad overviews of their research portfolios, including highlights of current collaborative efforts that address some aspects of hybrid and coordinated energy systems. The labs were strongly supportive of collaboration being a key component of innovation and of providing sound guidance to the build-out of the nation's future energy infrastructure. And, INL, NETL, and NREL are in a unique position to collaborate across energy sectors to advance technologies across the board. Common views included developing coordinated power, transportation, and industry energy systems as well as developing hybrid energy systems. A significant point of collaboration that was discussed involved integrated energy systems where fossil, nuclear, and renewable energy all contribute to a resilient, reliable, flexible, and balanced energy ecosystem. Analysis tools still under development and being used by the labs can be standardized to apply consistent boundary conditions and criteria for comparing outcomes. Working with key stakeholders - including industry - and with technology and policy goals in mind is recognized as a best practice for advanced analytic efforts.

Additional topic areas representing collaboration opportunities identified through the exchange included:

- High performance computing

- Co-development of dynamic systems modeling tools for co-simulation with unit operations

- Valuation of baseload and intermittent generation, including definition of metrics

- Energy state awareness

- Physical and cybersecurity

- Data science and big data analytics

- Advanced sensors and instrumentation

- High-level (front-end) to low-order unit operations control systems

- Subsurface science

- Smart materials

- Precompetitive consortia with industry.

Each of the above ideas represents potential programmatic research thrusts that, when organized and structured, offer critical S\&T innovation opportunities that would benefit multiple technologies. And, in particular, they are highly valuable to hybrid and coordinated energy systems.

\section{Session 3. Coordinated Energy Systems}

As the U.S. electric grid evolves, greater coordination among energy systems (i.e., fuel sources and supply chains, generation assets, distribution infrastructure, and end users) will be required to ensure resilience, reliability, and economic benefits. Coordinated energy systems typically refer to geographically distinct resources that interact through infrastructure, such as the electrical grid, a natural gas network, or the food-energy-water nexus.

Coordination typically occurs via market mechanisms. R\&D opportunities to increase energy resiliency and flexibility were a dominant theme for the coordinated energy systems session of the workshop. Major issues include system evolution (e.g., transition paths from today's system); 
infrastructure needs; interdependencies between electric, heat, and chemical energy; and control and cybersecurity issues.

Key R\&D challenges identified include:

- Diversity and coordination among energy sources (fossil, renewables, and nuclear) provide resiliency and flexibility; however, there is a need to address the barriers to achieving these benefits.

- Achieving increased resilience and flexibility will require identifying economic energyrelated products and understanding market constraints that inform technology opportunities.

- Metrics that quantify the value of greater coordination among energy systems should be developed.

- With the increased availability of natural gas in much of the United States, there is a need for a robust R\&D program to consider the full spectrum of natural gas supply, distribution, and use — as a fuel for both electricity generation and industrial boilers — but also as a chemical feedstock.

- Developing methodologies to understand the food-energy-water nexus and using this understanding to identify advanced energy technology needs.

Opportunities for collaboration included:

- High-risk coordinated energy system R\&D: development of approaches to leverage DOE investment to achieve the capital investments needed for large-scale research

- Development of R\&D roadmaps for new technologies and approaches-for example, heat integration, hydrogen, natural gas utilization, and dynamic interactions with the grid

- Unification of assumptions and modeling approaches across the national laboratory complex and among the applied energy offices

- Leveraging of facilities via data sharing, virtual integration, and researcher access across the lab complex for demonstration.

It was broadly recognized that a single-solution architecture or combination of technologies would be inappropriate for all regions. Instead, a robust R\&D approach should identify and develop a suite of technologies and approaches that will enable solutions that address local preferences, utilize regional resources, and are appropriate to the regional geographic considerations to enhance the reliability and resiliency of the entire energy ecosystem. Research to enable greater coordination of energy systems must broadly consider all energy sources as well as their varied uses.

\section{Session 4. Tightly Coupled Hybrid Energy Systems}

Tightly coupled hybrid energy systems refer to integrating multiple technologies with various time constants for reacting to system disturbances. These systems can increase the economic value of dedicated energy resources and independent systems through more efficient use of intermittent non-dispatchable, and underutilized energy sources. They can also provide a range of services to the grid, including power on demand and maintenance of power phase, frequency, and voltage, as well as multiple other energy products or energy-intensive products, such as chemicals, thermal energy for industrial processing or district heating, or water treatment. 
Creating a highly efficient, low-cost, tightly coupled energy system will require the development of interdependent subsystems that are connected through electrical and properly designed heat and mass transport systems. Tightly coupled systems must also be resilient to inherent or unplanned system perturbations. They require system-wide monitoring, state awareness, and application of supervisory or fully automated control systems that anticipate and adjust energy flows and unit operations in accordance with energy availability and market signals. Advanced technologies that could be part of future hybrid systems include:

- Thermal, chemical, and electrical energy delivery and storage systems

- Advanced power generation technologies, including hybrid systems that reduce exergy destruction (i.e., the loss of available work as heat, waste products, or electrical grounding)

- Advanced heat transport and heat exchangers

- Smart control systems and condition-based monitoring

- Cyber-secure communications and coordinated control

- Advanced fuel production and processing (fossil and nuclear)

- Stable water systems and natural water cycles

- $\mathrm{CO}_{2}$ capture and utilization.

Key R\&D challenges identified include:

- Optimizing the interoperability of the various technologies in hybrid energy systems to establish economic competitiveness through maximized use of capital; higher overall system operational efficiency flexibility, and reliability and meeting of environmental standards and other project-specific external objectives

- Developing and applying system simulation tools that accurately model energy and mass transport phenomena, physical system dynamics, and virtual control systems

- Applying digital real-time simulation with hardware testing in the loop to verify select system components, monitoring control systems, and system inertial traits that are difficult to model; and to verify and validate modeling tools and control algorithms

- Ensuring aggregated system stability during and throughout intentional control maneuvers and unplanned process upsets

- Applying cyber-secure process sensors and data fusion to support state awareness assessments, process diagnostics, and automatic or supervisor controls

- Developing resilient process controls that involve mixed human/automated control response

- Avoiding the risk of codependencies between the technologies, which would reduce flexibility and resiliency

- Managing intellectual property of individual energy companies that may be a roadblock to collaboration and coordinated operation.

Opportunities for collaboration identified included:

- Development of a modeling "toolkit" of extreme events that covers complex technological interdependencies and challenges of the power sector

- Collaborative design, testing, and verification of tightly coupled energy system configurations, as part of a national test bed 
- Smart control systems and cyber-secure communications and control

- Innovative technologies and processes for $\mathrm{CO}_{2}$ capture and utilization

- Development and application of system modeling and optimization tools that cover the entire range of energy sources and breadth of hybrid opportunities.

Tightly coupled hybrid systems offer enhanced resiliency and the ability to quickly recover from disasters through the use of multiple generation technologies. Workshop participants discussed a goal of developing a power system with high efficiency, resiliency, reliability, and low cost of energy under load following and flexible operations. To ensure a highly resilient, tightly coupled hybrid energy system, research should be conducted to develop a "toolkit" or database of extreme events that could impact energy systems operation against which models could be tested. Simulation of integrated system operation would offer insights for possible technology combinations and systems integration concepts that are region-specific, considering local resources, transportation options, and local market needs and preferences.

\section{Session 5. Technology Development Opportunities}

Technology development opportunities vary across sectors and include enhancement of existing assets and future transformational technologies. Specific technology advances were proposed and discussed for each energy sector. Examples of these are provided in Table 1. Most of these technology needs are common to all energy sectors. Because these advancements can be applied to multiple generation technologies, or in tightly coupled hybrid systems, they represent collaboration opportunities.

Table 1. Technology Development Opportunities Identified by each Energy Sector: Illustrating the Benefit of Collaboration

\begin{tabular}{|c|c|c|}
\hline Fossil Energy & Nuclear Energy & Renewable Energy \\
\hline $\begin{array}{l}\text { - Efficiency } \\
\text { - CO2 control } \\
\text { - Flexible and resilient power } \\
\text { - Water management } \\
\text { - Control of pollution/waste } \\
\text { - Hybrid microturbine/fuel cell } \\
\text { configurations } \\
\text { - Thermal energy storage }\end{array}$ & $\begin{array}{l}\text { - Flexible and hybrid-capable } \\
\text { reactors } \\
\text { - Reactors for distributed, } \\
\text { versatile, and dispatchable } \\
\text { operations } \\
\text { - Dispatchable thermal energy } \\
\text { delivery systems } \\
\text { - In-pile sensors } \\
\text { - Advanced fuels and } \\
\text { materials } \\
\text { - Supply chain improvements }\end{array}$ & $\begin{array}{l}\text { - Next-generation materials } \\
\text { - Hybrid power generation } \\
\text { approach } \\
\text { - Waste to energy systems } \\
\text { - Geothermal advancements } \\
\text { - Electrochemical process }\end{array}$ \\
\hline
\end{tabular}

Key R\&D challenges identified include:

- Enabling advancement of all power generation sectors simultaneously by focusing on storage, materials, security, and supply chains

- Developing hybrid or integrated energy systems with the ability to load follow, allowing for flexible operation according to consumer needs

- Developing standard methods to measure multiple metrics to value future energy system attributes; defining their "objective function" and constraints 
- Integrating cybersecurity measures during the development of new technology and systems (cyber-informed, consequence-based engineering)

- Leveraging transformational technologies such as additive manufacturing and predictive maintenance in power generation

- Implementing hydrogen at scale in the power sector and in industry

- Converting $\mathrm{CO}_{2}$ into marketable products (via reductive chemistry)

- Utilizing big data from an applied lab perspective (i.e., focus on the application rather than data science)

- Decreasing cost to enhance technology marketability

- Developing tools and methods to enable a "systems-of-systems" approach that looks both from the top down as well as the bottom up to seek innovative options and transformational concepts; focus on "what-if" scenarios

- Optimizing existing legacy and future transformational assets.

Opportunities for collaboration identified included:

- Materials design, synthesis, and characterization

- Novel $\mathrm{CO}_{2}$ reduction science, devices, and processes

- Novel thermal energy materials and systems

- Design and simulation tools

- Development of a coordinated strategy to address cybersecurity.

Focusing on commonalities such as energy storage, materials, security, and supply chains will offer DOE and the nation unprecedented opportunities for high-impact, high-leverage R\&D innovation across the applied energy portfolio.

\section{Breakout Discussions}

\section{Tools and Capabilities}

Several tactical steps were defined in the Tools and Capabilities breakout session that will aid in broader development of a strategy for future energy systems. These initial steps are categorized within modeling and simulation and experimental systems, as described below. The goal for energy systems evaluation and selection is robust decision-making under uncertainty to determine optimal energy system solutions, utilizing input from:

1. A wide array of modeling and simulation tools and analyses

2. Component and system-level demonstration and testing.

\section{Modeling and Simulation}

An array of modeling and simulation tools are available across the DOE lab complex to evaluate energy systems, energy markets, and the technical performance of individual components. Many similar tool sets approach questions from a different paradigm, making different assumptions regarding current and future performance, opportunities, and other variables. It is important to understand the unique roles each of these tools and approaches plays in assessing energy system performance so that results can be applied appropriately and in a complementary fashion. Workshop participants identified several steps to enable coordination of modeling and simulation activities with the goal of achieving a common understanding: 
1. Define key functional areas for energy systems (e.g., key metrics and performance characteristics)

- Tool sets will be needed to quantify multiple metrics and the interaction among those metrics.

- Metrics will need to be defined clearly, with the definitions being agreed-upon.

2. Identify computational tools available to assess these functional areas-produce a matrix of these tools

- Conduct a survey of applicable tools across the DOE lab complex, academia, and industry; identify lead labs and contributors for each tool or analysis approach

- Conduct a workshop to review available tools, identify gaps, and set "standardization" approaches

- Engage stakeholders and regulators

- Identify model complexity level_for example, easy, medium, or expert

- Models will be needed at varied scales of accuracy and complexity to support decision-making at various stages

- Determine whether a model has been validated or identify what is needed for verification and validation

- Establish best practices across the community

3. Develop a modeling framework with the various tools that allows for big-picture, holistic modeling with targeted outputs (i.e., an inter-sector energy model)

- Technology-rich, with high spatial and temporal resolution; compatible with exascale computing

- Requires commonality of assumptions, or transparency of assumptions

4. Serves as a computational test bed for performing numerical experiments, optimization, and uncertainty quantification.

- Establish a live database of models and associated data (versus a fixed database) for evaluating a variety of energy systems, market scenarios, and technology and system innovations.

5. Develop a standard collaboration platform

6. Incorporate data analytics

7. Define and analyze various integrated energy system scenarios using the suite of simulation tools.

\section{Experimental Systems}

As with modeling and simulation, several facilities are available across the DOE complex, or within industry and academia, and could be applied to advance integrated energy system R\&D. These facilities could be leveraged via virtual integration (e.g., connection via real-time data), and these virtual integrated systems could provide enhanced capabilities for verification and validation of simulation tools. Participants identified several steps to enable coordinated use of experimental facilities: 
1. Develop a database of experimental capabilities and gaps

- Designate a point of contact for each facility to manage experiment interfaces

2. Establish a framework for robust, "informed" design of experiments

- Use computational tools for improved experiment design

3. Establish interconnectivity of geographically disperse systems to maximize benefit at the least cost; this interconnectivity requires a:

- Standard for communications protocol among platforms

- Data management protocol for high-value, dynamic experiments.

Additional considerations for experimental systems include:

- Need data to drive models; experiments need to be carefully designed to ensure the necessary data were captured.

- Interconnectivity between laboratories may need to be real-time.

- Requires determination of what data needs to be exchanged and at what time resolution

- Some data sharing may not need to be real-time (e.g., use of data sets from one test or laboratory as a boundary condition for other tests or experiments)

- Model-driven experiments

- Hardware-in-the-loop testing combined with reduced order models (digital twins)

- Use models to develop energy system control strategies that can be tested robustly in hardware-in-the-loop systems.

- Possible models for a new multi-lab program include an "Energy Systems Integration Lab Consortium."

- Review best practices and lessons learned from the Grid Modernization Lab Consortium and other DOE multi-lab initiatives.

\section{New Technologies}

Participants in the New Technologies breakout session attempted to synthesize ideas discussed during the first day of the workshop, which centered on both the meaning of scale, regional differences in energy systems, and the interconnectivity of energy. Characteristics of systems to be developed by DOE through the labs emanate from the long-term perspective, intrinsic to national laboratories, regarding technology development, which involves:

- Holistic view of energy

- Economic stability

- Environmental sustainability

- Energy security

- Geopolitical security. 
So, commonalities such as storage, materials, and security were emphasized. Those participating in the breakout session reported four main areas for collaboration:

- Thermal storage - solid, phase change, thermal chemical; thermal pumped storage

- Carbon capture and utilization +: Reactive capture, hydrogen utilization, use of products.

- Solid oxide fuel cells +

- Separations and recycling of critical and other materials, including water and sustainability.

These four areas could encompass pathways developed at earlier "Big Ideas" summits held across the labs. The "plus" signs $(+)$ indicate the desire to move beyond current program lines to leverage synergistic lab capabilities.

\section{Thermal Storage}

Over the past decade, the growth of intermittent renewables has fostered significant interest in electric energy storage, especially the use of batteries. Less research has focused on developing the potential of thermal energy storage. Thermal storage could be used to alleviate temperature cycling in coal plants while enhancing flexible output. So-called "pumped thermal" storage methods could buffer fossil or nuclear generator output to meet widely variable daily grid demands. Projected costs for pumped thermal are comparable to pumped hydroelectric, but with no geographic or land-use issues. This type of energy storage at a thermoelectric plant would allow flexible output while ensuring the availability of base-load generation when extreme weather curtails wind or solar supplies.

\section{Carbon Capture, Utilization and Storage Plus (CCUS+)}

Manufacturing of hydrogen from fossil systems could be integrated into the DOE H2@ Scale initiative, joining a nuclear-wind hydrogen concept. Developing supercritical $\mathrm{CO}_{2}$ cycles to apply to different prime movers would also fit under CCUS+. Combining the use of microbes and the use of waste $\mathrm{CO}$ and $\mathrm{CO}_{2}$ could lead to high-value products. Making products while also capturing $\mathrm{CO}_{2}$ - reactive capture - offers promise. Gasification of coal or hybridization of natural gas and biomass to produce hydrogen, fuels, or power could complement ongoing renewable-nuclear hybrid analysis. Manufacturing oxygen along with hydrogen at scale could be considered.

\section{Solid Oxide Fuel Cells Plus (SOFC)+}

Solid oxide fuels cells, which are currently part of the FE program, could be deployed in distributed generation applications with synergies to solar photovoltaics, energy storage, and other direct current energy sources. Fuel-flexible hybrid gas-turbine/fuel cell systems are being developed to raise the efficiency of power generation to $70 \%$. Future hybridized configurations of SOFC with small modular nuclear reactors could also be explored.

\section{Separations of Critical Materials and Use of Water}

New technologies require critical minerals and materials (e.g. rare earths, nickel, lithium, and cobalt) for which the exploitation and processing has yet to be comprehensively analyzed from a sustainability perspective that includes both energy and water intensity. Hybrid cooling water technologies for thermal applications is an area ripe for further R\&D as water sufficiency issues continue to mount. 


\section{Cybersecurity}

Cybersecurity is one aspect of secure and resilient energy systems; other aspects involve physical security from both human and natural threats. Security is focused on protecting people, information, and physical assets. That protection extends from preparing to avoid events to safely withstanding events and finally to recovering from events.

Cybersecurity is arguably the security aspect that is now undergoing the greatest changes, and thus, it is the one with the greatest needs and opportunities for applied R\&D. Thus, cybersecurity for energy systems is likely to have opportunities to adapt best practices both from other aspects of energy security and from the implementation of cybersecurity in other domains (e.g., information technology and banking).

One key cybersecurity development opportunity is to incorporate cybersecurity in all stages of energy system development, starting with the initial stages. That involvement could involve conducting attack system analysis at each development stage to (1) identify security requirements and (2) design the energy system and the cybersecurity aspect of it simultaneously. Co-design has been found to result in lower-cost systems with higher security in other domains. Methods for attack system analysis for the energy sector are not yet mature, so they would need to be developed and would likely consider information exchange and decision methods. Related development opportunities involve developing the tools, methods, and training techniques to perform constant threat analysis to identify key threats and estimate their potential impacts.

A second key cybersecurity development opportunity involves a new discipline: cyber-informed engineering, which focuses on:

- Methods to measure security complexity and quantify sufficiency

- Methods to constrain complexity especially in dynamically sufficient systems; these methods could include modularity, anomaly detection tools, and digitally-informed prognostics.

- Methods to address dynamic simulation, including those that provide situational and state awareness

- A cybersecurity capability-maturity modeling tool.

Additional opportunities include:

- Augmentation of existing engineering standards and ownership issues

- Study and quantification of autonomous energy system security performance especially for self-configuration and healing systems; the effort should consider dynamics and distributed versus centralized security options

- Design of security for transactions and markets.

One way to initiate a cybersecurity development effort involves using a near-term case study that could involve an existing class of equipment undergoing a technology evolution. The effort would involve implementing some cyber-informed engineering practices and quantifying the value of addressing cybersecurity issues. Lessons learned through that effort would help identify specific gaps and R\&D needs. 


\section{Synthesis and Pathway Forward}

The workshop addressed key issues where system-level integration of the U.S. energy use sectors (i.e., electricity, transportation, and industry) ensures U.S. competitiveness by domestically producing energy products and services using U.S. natural resources in a responsible manner that values both the present and future generations. Strategies emerged that would reduce the overall cost of energy by providing increased operational flexibility, increased efficiency, higher utilization of generation assets, and higher quality of energy services provided by the system. Future collaborations between the applied (and other) national labs were identified that would enable advancements in technologies meant to secure reliable and affordable energy for the American public. Through collaboration, renewable, nuclear, and fossil energy R\&D efforts have the potential to pursue unique strategic R\&D to innovate key enabling technologies; evaluate, design, build and validate hybrid systems; elucidate optimization and control schemes; and contribute to a resilient, affordable, secure U.S. energy system.

The input of the workshop participants indicated multiple unique, high value-added areas of collaborative R\&D across the applied energy programs of DOE. Recognizing the high potential for hybrid and coordinated energy systems for the United States, participants identified four topical areas for new or enhanced S\&T efforts:

- Integrated systems analysis, modeling, and optimization, including developing tools for unprecedented understanding of the U.S. energy infrastructure and interdependencies

- Integrated systems engineering, development and testing, including developing and investing in testing and verification of new architectural frameworks across all supply and use sectors

- Innovative, core, multi-sector and multi program technologies, including developing technologies that will enable highly efficient, resilient, and affordable tightly coupled energy systems.

- Approaches for security and resilience of integrated energy systems.

Each of these areas, as discussed above, has multiple aligned outcomes that are critical to enabling the U.S. industry to better utilize the spectrum of U.S. natural resources in achieving energy security, ensuring economic stability, and addressing environmental sustainability for the foreseeable future. The outcomes form an initial basis for formulating detailed R\&D roadmaps that collectively would - as an "Integrated Energy System Initiative"-offer compelling highimpact innovations that are uniquely aligned to the missions of the DOE and its lead national laboratories. 